\title{
Designing Familiar Open Surfaces
}

\author{
Kristina Höök \\ Swedish Institute of Computer Science (SICS) \\ Isafjordsgatan 22, SE-164 29 Kista, Sweden \\ kia@sics.se
}

\begin{abstract}
While participatory design makes end-users part of the design process, we might also want the resulting system to be open for interpretation, appropriation and change over time to reflect its usage. But how can we design for appropriation? We need to strike a good balance between making the user an active co-constructor of system functionality versus making a too strong, interpretative design that does it all for the user thereby inhibiting their own creative use of the system. Through revisiting five systems in which appropriation has happened both within and outside the intended use, we are going to show how it can be possible to design with open surfaces. These open surfaces have to be such that users can fill them with their own interpretation and content, they should be familiar to the user, resonating with their real world practice and understanding, thereby shaping its use.
\end{abstract}

\section{Author Keywords}

Design for interpretation, open surfaces, appropriation

\section{ACM Classification Keywords}

H5.m. Information interfaces and presentation (e.g., HCI): Miscellaneous.

\section{INTRODUCTION}

Whenever users can fill in some field with text, pictures or some other media that are then shown to other users, we typically see all sorts of innovative ways of communicating through these fields - no matter how small and restricted they are. For example, some mobile phones have Bluetooth and you can name your Bluetooth as you please with a few letters. Bluetooth currently transmits in about a 10 meter range and other people with Bluetooth-enabled devices can see the names of the nearby devices. This in turn makes people name their Bluetooth device all sorts of innovative names, such as "single, blond, available" or "Bajen 2003" (where "Bajen" is a major Swedish football/ice hockey team) [25]. These names are not pushed to others nearby they have to turn on their Bluetooth and then search for other Bluetooth-devices around - not a very efficient means of communication one might think. And still some users find it intriguing and will occasionally have a look around to see who else is there and how they named their device. This use of Bluetooth is not the one intended by the developers of Bluetooth-technology, the only reason you name them is in order to connect, for example, your ear-piece with your mobile phone.

This example illustrates what we mean by appropriation, that is, situations in which users take some technology into use in a way that moves beyond the original design intention. In HCI-literature this is either documented as something fascinating and positive that proves that people are more creative, innovative and interesting than most designers expect, but it can also be documented as a failure by the same reasoning: the designer has failed to take real people and their practices into account and if this happens it should be read as a failure in the design process.

The main question, which I have not yet answered but want to address in some small ways here, is whether we can design for appropriation. Can we open some of the surfaces in systems for users to inscribe their own interpretation and actively contribute to it so that the functionality may drift with their usage? What can designers do in order to allow for, enable and even encourage usage that over time changes the meaning of the system/application/ service being built?

What we are looking to describe here, is one particular form of design for appropriation - it builds upon what is familiar to people in their everyday communication practices with others and everyday physical, bodily encounters with the world. The theoretical home of this work is in embodied interaction [8]. With the widespread networking of computers and other devices, the number of social applications immediately grew. In those applications, as soon as users realize that they can observe parts of others' behaviors or even communicate, they can start making sense or both others and thereby their own activities in the system - a social affordance [31]. If the application is built in such a way that those social activities of the end users are also allowed to alter the contents, functionality or possibilities for communication between users, the system can "drift" 
over time - allowing users to be co-constructors of the system over time. Similarly, we can design for our everyday bodily experiences of the world allowing similar processes of interpretation and appropriation. Our focus has been on embodied emotional expressions enabled through physical, sensual and tangible interaction.

In here, we will revisit five of our own applications in which appropriation has happened both within and outside the intended use. Our aim to start the discussion on how to design for appropriation through tapping into processes that feel familiar to us, either through social practice or bodily, tangible interactions.

\section{TRACING THE ORIGINS}

Participatory design is one of the most important movements within HCI-development, leaving traces in most standard methods used in interaction design [28]. Most new software projects will attempt to get users involved at some stage of the design cycle. The message that it is the users who will best be able to express what kinds of functionality is needed, rather than managers or sales people, is probably for the most part an accepted fact. But the original movement was something more than just involving users in the design process as a way of ensuring that the interaction design and functionality is correct and usable. Participatory design grew out of an ideological stance where the aim was to give workers the power over both the workplace changes and the tools they have to use in their daily work. It was an attempt to follow the Scandinavian ideal at the time as expressed by e.g. the co-determination law providing employees with more power over their workplace [2]. This is why the methods tried to ensure that ample time was provided in the project to educate the prospective users about the possibilities given by software. Rather than having software experts deciding what could and should be created, the users could actively part-take in the design process and put real demands on the design.

This is of course a cumbersome and difficult process that has been later criticized for many different reasons. It does not meet the fast development cycles we see today, and the prevailing perspective in most software development companies is probably not that of giving users power over the design process. Some claim that it does not deliver what it promises. The resulting systems are not necessarily better or more innovative changes to the workplace processes than those produced with less time-consuming design methods.

What we aim to discuss here is not participatory design processes and their merits as such, but instead whether there are ways of picking up on the same underlying values in a different way to ensure that users are given some power over the system. Our aim is to discuss how we can create designs that, within certain limits, allow users to appropriate the system once it is built. In our view, allowing users to appropriate and leave their marks on the tools they are given, is one of the important values of the participatory design movement. We are currently seeing a wave of de- velopment of technology undermining the fragile power relationship between those who produce the software tools and those who will have to live with them. The so-called pro-active computing stance expressed in research fields such as (parts of) ubiquitous computing, affective computing and intelligent environments, is oftentimes, not always, reducing users to information processing units that can be modeled and understood, and then the system can act on their behalf. Many of these systems remove the power from users entirely. Sometimes this can make a lot of sense, especially if the situation at hand happens in a context that is limited enough to be modeled in all its details and consequences. This is true for some time-critical tasks, such as flying an airplane in certain situations, or in health threatening situations, such as falling asleep when driving your car. But for most applications, the tool-based view putting the user at core still holds: systems should be designed as tools that users can make use of in ways that suit with their tasks and needs. Thus, the user needs to have more power and the system needs to be transparent and allow for various kinds of appropriations.

In here, we want to show that no matter whether we include users in the initial design process or not, we may or may not build systems that in the long run will communicate the values originally intended by the participatory design movement.

Participatory design makes (some) users part of the design process leading up to the launch of a system. Once the system is launched, the system design is typically seen as settled once and for all. One problem to this kind of system development perspective is that systems have to be maintained and might be changed in later development cycles. In those cycles, it is unclear when the changes to the interaction are so substantial that users should be brought in again. Many HCI-consultants complain that the careful layout and interaction design created originally for the system is entirely destroyed later on when various system developers/maintainers tinker with aspects here and there in the system. A second problem with participatory design is that the users who took part in the original system design might only represent a fraction of the future users. Anecdotal stories from participatory development processes talk about making the participants 'hostages' in the development process. They get to be educated in system design and understand why certain aspects of the system are created in a certain way. The rest of the users who have not gained such insights, are less enthusiastic and typically react in the same way as if the system had been design without involving the 'hostage' group in the design process in the first place.

In a sense, there is no guarantee that just because the design process was democratic and involved users, the end result will also be such a tool. The same problem arises with the Value-Sensitive Design (VSD) method [13] where users involvement in the decision process will not necessarily lead to a final solution that is un-biased and conveys the values intended. In VSD various stakeholders, both direct 
and indirect, are brought into the early decision face putting their needs and priorities on the table. These 'values' are then balanced against one-another aiming to make the final solution, be it a software system or a city planning process, a well-balanced solution catering for everybody's needs.

\section{Not Workers but Consumers}

During the end of the 90'ies and up until now, we have seen an important and very interesting shift towards seeing users as something more than being efficient, involved workers. It is a reaction against the rationalized, efficiency perspective on what people can and should be doing in their life. The ludic aspects of life, play and fun, as well as the inner life and especially emotions, have been put into focus [14, 23]. A shift towards finally, after centuries of separation, integrating body and mind has moved throughout the research world, all the way from neurology, psychology to design of information technology [7]. It is now perfectly respectable to do research in computer games without having to disguise it as research on something else, like children's learning or game theory to aid market negotiations. Instead, we can focus on trying to understand what makes something fun and playable with the sole purpose of being just that: fun and playable.

At the same time, information technology products has made its way out into the society, moving out from the work place into almost every aspect of how we live our lives. The mobile and ubiquitous technologies have gained grounds and computers are no longer solely PCs placed on our desks at work or somewhere in our homes far away from the kitchen or living room. Computers are nowadays something that we carry in our pockets, integrate with our home entertainment systems, communicate through and with in almost every imaginable context - while on our boat in the archipelago, on the bus, or in the shopping mall. The shift from focusing on work contexts to consumer markets is obviously following this movement.

As we move outside the work place into consumer markets, we are moving into a new problematic arena where power distribution between those who produce systems and those who get to consume them is quite different. In the work place, we could rely on the workers and unions as possessing some power and being interested in influencing the values and needs of people in a longer perspective than a moment-for-moment consumism. In the consumer market, the only power at hand lies in whether we buy or not buy the products that are put out there for us. Some claim that our current culture is making us infantilized [5] - we consume without reflection, and do not engage in deep relationships with one-another or with the deeper more hard-gained values in life. Thus, people are lulled into being good consumers and buyers, believing that buying and owning is the key to happiness. Be that as it may, we are certainly competing for the buyers' attention when we put out products on the consumer market. Products that require more from us as consumers, for example, encouraging us to reflect [27] and take an active stance, will have to make use of the same beautiful surface and seductive packaging in order to compete on this market. (Alternatively, we may reduce ourselves to producing systems for museums or art installations.)

In our view, the problem we need to solve is a design problem, and the powers now lie with the designers and those who employ them. The consumers do not have any powers over the products they are given - the powers are in the hands of the designers and what they decide to provide us with. We need to show that users will indeed like and buy systems where their own interpretation and appropriation of technology is a market advantage.

\section{Being Steered by (Seemingly) User-Centered Slogans}

The competition on the market is fierce. The companies struggle to create products that their consumers can very easily pick up already in the store and use right away without having to bother about complex technological issues. It becomes very hard to argue that users should be let into the system in such a way that they can make sense of the technology and perhaps even start demanding solutions that protect our privacy, can be appropriated in innovative, artful ways or some of the other values that we aim to argue for here. Instead, simple slogans are allowed to steer whole industries towards technological goals that sound seductively correct, helpful and human-oriented. The telecomindustry, for example, puts millions into working towards a goal such as "users should not have to bother about network connectivity or which network technology is in use - they should always be best connected seamlessly". On the surface, this all sounds fine, who would not like to stop bothering about network connectivity? Most of us who try to live in a combination of wireless network technologies spend painstaking efforts and huge amounts of time on trying to figure out the problems that arise from today's mismatch of computers, mobiles and network technologies.

But these slogans also entail problematic values. To achieve the goal of e.g. seamlessness, network connectivity needs to be hidden from users' view. We will not know how we are connected, the cost of the connection time, and the system will pro-actively do things on our behalf.

Other examples of user-centered slogans that we perhaps should be more suspicious of are, for example, "users should not have to adapt to systems, systems should adapt to users" [18] or "systems should address users emotional states so that they do not increase stress levels or fail to address users real needs" [24]. Underlying such slogans are reductionist ideas that it should be possible to understand human thinking and sense-making if we only model enough of the signs and signals we transmit. Technology has the power to change our behaviors, our values and even the way we see ourselves, and thus a reductionist position risks enforcing a machine-like view on our minds and bodies. 


\section{THE DESIGN MATERIAL}

Our aim is to address the same values as the participatory design movement but this time for the consumer market. Users should be empowered with the rights to shape the systems that are put into their hands. We also want to move beyond slogans that may seem very user-centric, but that are instead making it harder to users to appropriate and bend technology to fit with their needs, ways of acting and dreams. Furthermore, our focus is on what happens once the design is completed, the system is in place, and the users are trying to take it into use, not on how to involve users in the design process as such. Thus the problem addressed here lies more in what happens once the system is in use.

\section{Inhabiting the Computing Material}

If we see system design as a building where the walls have been set up, the floor is laid, the roof is securely in place, we also know that once the building starts to be used, people will start leaving their traces in it. They will put up wallpaper, furnish it, sometimes tear down walls to create the kind of spaces they need for the kinds of activities that the building will host over time. Depending upon the activities in the building and the traces they leave in the physical layout and social activities, new visitors to the building will be able to 'see' how to act, where to interact, whom to talk to. The space will be turned into a place as phrased by Harrison and Dourish [16].

There are two important aspects of this activity that we need to consider. First, it is important to remember that meaning will not arise from setting up the walls. Meaning is created by the people and their activities in the space. Second, the design of the building seems to be an on-going process where certain spaces are left 'open', inscribable, sometimes purposefully by the architect, sometimes because the inhabitants takes charge of the house and rebuild it, but in any case, allowing for the inhabitants of the house to leave their marks on it.

If the architect has made a very strong statement in the building design, it might be harder for users to appropriate the building. They will hesitate to change it because they are scared of destroying the intended meaning. Nevertheless, over time the activities do leave their marks on it - it gets worn, wallpapers have to be changed, new tenants move into the house.

What is truly interesting about computer system architecture is that it is so much easier to change. A computer system is not built by bricks and wood, but in software that is a fantastically fluid and changeable building material. In a sense, the democratic values expressed by the participatory design movement, is so much more easily expressed in this software material than in the brick and wood of a building or the design of a work tool like a hammer. While not trivial, it is not impossible to provide the end users with substantial power over both the 'material' and the content.

As users can leave visual or other traces to one another inside these systems, the basis for inhabiting the building and shaping it for use arises. We can enter some of the qualities that the physical world offers through such a 'social computing material'. For example, in the physical world, stairs in an old house may start to look worn, or a book may convey traces of repeated reading. Similarly, but conveyed in quite a different way, parts of the surface of a website can start to look worn in the sense that you see that many users before you have bought a particular book, downloaded some piece of software, or listened to the same music as you do. These cues help us orient in the large spaces inside the digital world.

In physical settings, cultural norms and behaviors are conveyed through a dialectic relationship between the shapes of the spaces, watching others behave and learning over time from these cues. We whisper in a library, walk slowly in a graveyard, cheer in audiences at sports events and tap our feet in rhythm at jazz concerts. As discussed by Asplund these behaviors are not once and for all given, but are invented and re-invented in the moment [1]. As most of computer and mobile use is constrained by the display and keyboard, these social cues are mainly conveyed through what is written in dialogues between users. From the conversations and dialogue that others are engaged in, we can pick up on what kind of place we are entering.

There are a number of attempts to address these dynamic qualities and change of system functionality over time that we shall not be addressing here. One is to make the endusers program their own environments. Sometimes such environments also allow users to share the solutions they have created with others. While we find this interesting, it is also quite problematic as most users will not have the formal training to create the kinds of functions they need nor to oversee the consequences of installing them into already complex environments. Still, there are many fruitful examples of functioning systems, such as creating macros desktop applications. Another such solution that we will not address here, are the so-called user modeling systems. While they also attempt to address the problem of changing the functionality of a system over time, they rely on abstracted, formal representations and therefore often fail [18]. Users' lives and ways of appropriating systems is much more messy and improvised than what those adaptations can support (see argumentation in, for example, Suchman [29]). 

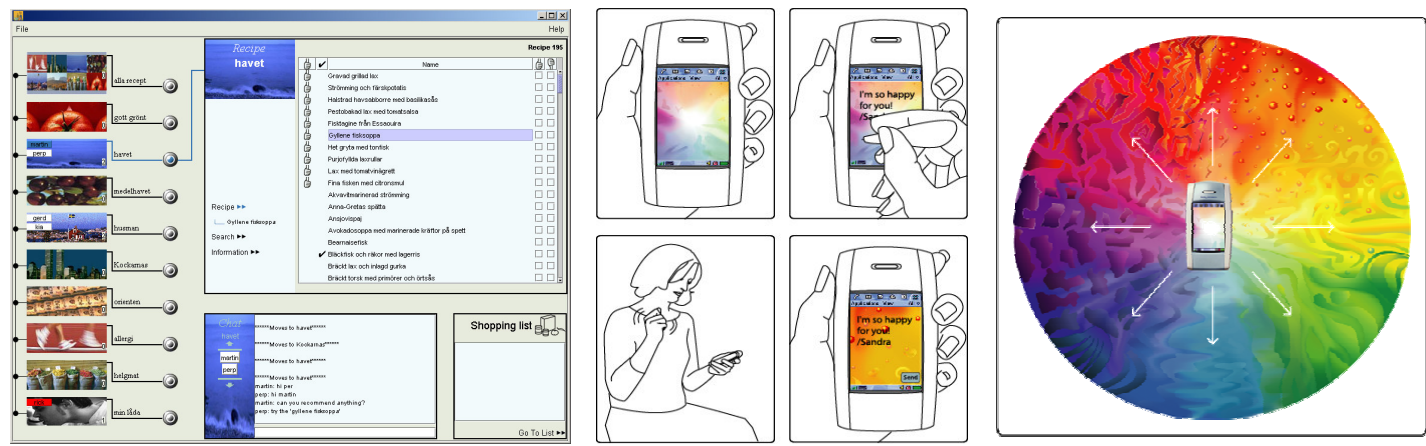

Figure 1. From left to right: Kalas, eMoto interaction and eMoto-circle of expressions.

Our way of addressing appropriation has the same roots and thinking as the ideas behind ambiguous design [15], defamiliarisation and reflection in design [27]. In designs by these researchers, it is the user's interpretation that will give the system its meaning, and the user's interpretation will be key to what the system is used for. In a sense, what they are doing is to force users into a situation where they have to appropriate the systems. There is no other way of using the system because they do not appeal to any, to the users, familiar form.

Take for example the Miró-system [3]. It attempts to display the mood of an office through a Miró-painting that changes with emotions that people at their workstations put into the system. The resulting changes in the painting project on a wall are not straightforward and simple to interpret but are created from making parts of the painting change.

When the painting was installed for a while in an office, people would come up to it and start interpreting it in ways that had nothing to do with how it really worked. It became some sort of conversation piece that allowed discussions about what people felt were going on in the office, such as worrying about the deadline for handing in proposals for funding.

While defamiliarisation and ambiguity are powerful tools to enforce appropriation, it should be possible to build for appropriation from what is familiar to us. We should be allowing users to communicate with one-another in ways where they recognize each other or themselves in and through the media - sometimes socially, sometimes physically/bodily. Let me try and explain what this familiariza-

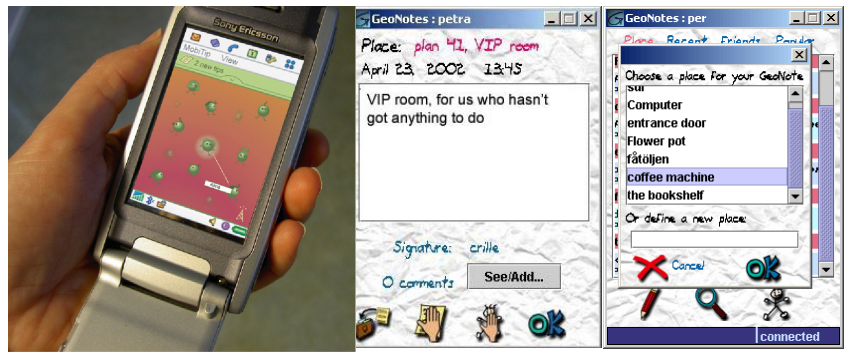

tion process may look like in five systems serving as examples on how open, but still familiar, surfaces can aid users to create their own usage, make sense of, and sometimes even appropriate systems for purposes beyond those envisioned by the designer.

\section{FIVE SYSTEMS: KALAS, GEONOTES, MOBITIP, EMOTO AND AFFECTIVE DIARY}

\section{Kalas}

The food recipe recommendation system Kalas, was built to explore an alternative way of navigating large information spaces - socially rather than spatially. The idea of social navigation is to aid users to navigate information spaces through making the collective, aggregated, or individual actions of others visible and useful as a basis for making decisions on where to go next and what to choose [31]. These social markers should also help in turning the navigation experience into a social and pleasurable one rather than the tedious, boring, frustrating, and sometimes even scary experience of a lonely user. The food recipe system Kalas makes use of several different forms of aggregated trails of user actions and means of communication between users: recommender system functionality (recommendations computed from others' choices), real-time broadcasting of concurrent user activity in the interface, possibilities to comment and vote on recipes, the number of downloads per recipe, and chatting facilities. Recipe author was also included in the recipe description.

In Figure 1 we see how Kalas has recommended a set of recipes through putting a "thumbs-up" symbol next to them. As users provide feedback on the recipes they download
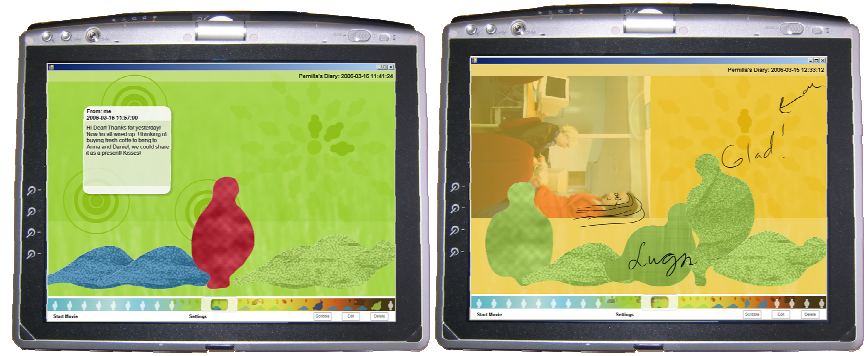

Figure 2. From left to right: MobiTip with BlueTooth-presence, a geonote placed in the "floor 41, VIP- room", the GeoNotes system with a choice of place-labels, and finally, two screendumps from Affective Diary 
(and cook) through either giving a thumbs-up or thumbsdown to it, they easily recognize and understand the aggregated trail represented by a thumbs-up. Beneath the list of recommended recipes, we see a dialogue between a couple of users. This small chat window makes it possible not only to talk about recipes, but also to exchange all sorts of tips and hints, and even chat about completely different issues. Once a recipe has been chosen, the user can also add comments directly relevant to the particular recipe. To the left in the Kalas-window, there is a list of recipe collections. When users log on and move to one of these recipe collections, other users will see their "label" pop up. The realtime presence of others and their choice of which collection to visit is thereby visualized. Thus, the Kalas interaction opens up numerous surfaces that users fill with their presence, comments, choices or chatting.

In a 6-month user study with about 300 users, we found that users picked recommended recipes despite not having reflected on the meaning of the thumbs-up symbol [31]. This led us to speculate that a lot of the social trails are created and used without users consciously noticing them. Social affordance and following users around might be activities that take place without users realizing it. For example, if asked why you go to a particular restaurant, you might say that it is because of the food but you will probably not say that it is because the other restaurant guests who frequent it. The social qualities added to the choice of food recipe but not in the same direct and accessible way as, say, recipe ingredients.

\section{GeoNotes}

After building Kalas, some of my colleagues, Per Persson, Fredrik Espinoza and Petra Sundström (Fagerberg), decided to try and move the idea of navigation based on the trails of others out into the physical world. GeoNotes is a mobile service that allows users to leave virtual post-it notes at difference places [9] through using a positioning system. As other users pass by a geographical location, they will be notified of the existence of any GeoNote placed there.

Obviously, the post-it note itself is an open surface that users may fill with different contents, but another interesting part of GeoNotes is the PlaceLabel-system [10]. As the positioning system used when implementing GeoNotes was not very fine-grained, the system instead allowed users to place their GeoNotes under different headings - placelabels. At each location, there was a set of pre-defined labels that users could pick, but they could also invent and name new places themselves. In a one-month field test with 78 users, the connection between the underlying hotspot system and users' perceived model of how places should be named were innovatively handled by the users themselves [10]. Place-labels were created by the end-users to post notes at places that covered smaller areas than the positioning offered by the system, such as "coffee machine", or even time-dependant places such as "the lecturer's fore- head". Large places were created by re-entering identical place label names at several hotspots.

In Figure 2 we see a list of choices of place-labels that a user may place his or her note under, but we also see a note placed under the header "plan 41, VIP room". This is an authentic note from a user who decided to create a virtual place - a floor 41 cannot not be found in any building in the test area where GeoNotes was studied. When interviewed, this user said that he and his friends had decided to create this place-label in all locations they encountered in order to create a virtual space for them to meet and make comments in - their own VIP-room. Using the building-metaphor from above, these users had appropriated the bricks and concrete of the GeoNotes-building and added virtual places to the geographically oriented design intentions. Once this usage appears, it of course makes a lot of sense, but it was not anticipated by the designers of GeoNotes. The placelabel system offered an open surface that users could appropriate and render their own, social meaning. They used it to build the taxonomy of places where none conformed in a one-to-one mapping with the geographical space [10].

\section{MobiTip}

Following and expanding on the ideas developed in GeoNotes, a system named MobiTip was created [26]. In MobiTip, users exchange tips when their mobile phones are within BlueTooth-range from one-another. Again, several surfaces were left open for users to appropriate. They could write any notes they wanted and exchange those with people passing by, peer-to-peer, and notes then propagated through passing from one user to the other.

In MobiTip the social space of nearby Bluetooth-enabled devices are visualized to the user in a presence display, see Figure 2. MobiTip users and other discoverable Bluetooth devices are depicted as animated icons. As the user moves among other people, icons will appear and disappear in the interface as the people carrying the devices move in and out of Bluetooth range. Users loved seeing the BlueToothnames of other's mobile phones and quickly understood the connection between these and their actual physical, social surroundings. As a consequence they often renamed their phone to something more legible in order to be seen by others. In the visualization, they could also see when tips where exchanged and could thereby understand the network infrastructure used in the system [25].

In addition to making MobiTip downloadable from a webpage, we decided to market the service by placing a computer with a Bluetooth-server and a screen in the window of a store in a shopping mall. On the screen we displayed nearby Bluetooth resources by name. This triggered a small group of users to sit around renaming their device to funny messages, such as "I am naked", or even try and create combinations of Bluetooth names to display something similar to fridge poetry. Despite the fact that this is an extremely small surface (a Bluetooth name can only be a few signs) users not only created meaning from seeing the 
names of other's Bluetooth-presence, but could also playfully appropriate it beyond our design intentions.

Through the MobiTip design we are, in a sense, exposing the seams - connections, gaps, overlays and mismatches within and between physical, digital (BlueTooth-enabled) and social space. Since it is possible to rename the BlueTooth-identity in the mobile phone, users could make sense of it and even, in a very limited sense, communicate through it. The functionality allows for active coconstruction (by the end-users) of connections between spaces, or for playful use of the seams themselves. Again, users understand this space through the familiarity created by seeing others and their own activities depicted in the system.

\section{eMoto}

In all the above examples, some surfaces are basically simply left open for users to fill with text, thereby creating their own combinations of physical, social and digital spaces. Through seeing the activities of others, they can infer and make sense of how their own activities will be presented - a 'familiar social process'. In our next project we had a slightly different question: is it possible to create a surface that has a more given, strong, artistic shape communicating its intended use and still allow users to appropriate it? We decided to try this out in the area of affective interaction and built the system named eMoto [30, 11]. In eMoto, users send SMSs between mobile phones, but in addition to text, the messages also have colorful shapes and animations in the background (see examples in Figure 1). The user writes the text-message and then chooses which expression to have in the background from a big palette of expressions mapped as a circle. The expressions are designed to express different emotional content along two axes: arousal and valence. For example, aggressive expressions have high arousal and negative valence and are portrayed as sharp, edgy shapes, in strong red colors, with quick sharp animated movements. Calm expressions have low arousal and positive valence which is portrayed as slow, billowing movements of big, connected shapes in calm blue colors.

A second, related, question for eMoto was to see whether we could design for familiarity that does not build on the social presence of others. Instead, we wanted to build upon bodily processes that feel familiar to and resonate with our physical experiences of emotions. Therefore, we designed a set of gestures that the user has to perform to move around in the circle of expressions to pick a particular background to the message. The user performs those gestures using the stylus pen (that comes with some mobile phones) which we had extended with sensors that could pick upon on pressure and shaking movements.

In eMoto, the messages someone gets from a friend or a beloved, only makes sense against a background of knowing the other person and typically you have to know the other person very well in order to make sense of the combinations of words they choose and which colorful back- ground they add to it. On the other hand, the messages are familiar to users because they also use the system, and thus know that in order to send a particular message, the other person will have had to perform certain gestures in order to arrive at that particular expression. This means that the meaning of the messages is not given by the system as such, but by the interpretation given by the two friends using it in ways that make sense to them.

We let five friends use eMoto for two weeks [30]. From their usage we saw that the eMoto-circle was not used in a simplistic one-emotion-one-expression manner mapping emotions directly to what you are experiencing at the time of sending an emoto. Instead the graphical expressions are appropriated and used innovatively to convey mixed emotions, empathy, irony, expectations on future experiences, surrounding environment (expressing the darkness of the night) and in general a mixture of their total embodied experiences of life and in particular, their friendship. We also saw that emotions are not singular state that exist within one person alone, but permeates the total situation, changing and drifting as a process between the two friends communicating.

The five friends also seemed to pick up on the gestures fairly easily and we got some interesting video clips of "real" usage where the user seems to be totally emotionally and bodily engaged with the system. While this was a short study, we believe that to some extent we were able to tap into 'familiar bodily processes' making users experience the emotions the gestures aimed to resemble.

\section{Affective Diary}

In the last system we are in the middle of building - the Affective Diary - we are again trying to address our familiarity with our own bodily experiences [22]. This time, we are not relying on social mechanisms in the system in order for the user to understand what is going on. Instead we attempting to mirror users' bodily experiences from their everyday experiences in the system and making them remember them by adding contextual data from their mobile phones (SMS, photographs taken on their mobile, BlueTooth-presence they have encountered during the day, MMS, etc). We do not make any inferences on behalf of the user, but leave it to them to make sense of their own experiences.

In our design (see Figure 2), we picked a narrative illustration with a humanlike character, shaped like an abstract 'body' representing the users day. The abstract, ambiguous, body postures symbolize users' state in a shape that directly connects the data obtained using sensors placed in a bracelet on users' upper arm. The system collects sensor data (pulse, pedometer, accerolometer picking up whether standing or lying down) and maps them into two dimensions: movement and arousal. Movement, represented in terms of how upright the 'body' is, is derived from pedometer and other sensor data. Arousal, represented by color of the 'body', is picked up from subtracting movement from the 
sensor readings and thereby finding peaks in pulse, sweat, etc., that cannot be explained by physical movement.

At the end of the day, the user loads all data into the computer and receives a graphical representation of the day. The sensor-data is fed into the animation of the body while the photographs, text messages, are placed above the body's head (see first screen dump in Figure 2 with the opened SMS above the "red" body representing arousal). The representation of the data can be played as a movie, animating the body morphing from one state to the next. The user can reflect upon the day, interpret and alter the representation through changing the body state or color, scribbling diarynotes onto the surface as well as manipulating the photographs and other data (see second screen dump in Figure 2).

Understanding your own emotions is an interesting and important learning process. Providing an affective ambiguously represented mirror of what you have experienced throughout the day could be a promising way to make inquiries about the hidden mechanisms of emotional experiences. The theoretical stance we take on emotions and emotions processing of is that of a cultural-constructivist view. An emotion is a felt and experienced inner life, which through the cultural lens and in dialogue with others and our environment is modified and processed over and over.

On a deeper level, we are exploring whether this kind of feedback could make people more aware of their own physical reactions, their stress levels, what makes them calm or even happy. Obviously, the interpretation of such high-level concepts can only be done by the users themselves but we can empower them to further explore their own physical reactions.

Our initial user trials with Affective Diary are promising. People seem to be able to read create their own interpretations based on the ambiguously represented body shape and color. They read much more into the representation than what is actually there. In particular, as they can see when the body changes shape and color and connect it to the mobile data, they can make sense of their own experience at the time. Users' 'familiarity' in Affective Diary comes from how the experiences are mirrored - we remember and recognize ourselves in and through the representation mirroring us.

\section{DESIGNING FOR FAMILIARITY}

From a user perspective, a system designed along the lines outlined above, is not only a tool to be used to complete a task with. Instead, in these systems the interpretation is left to users to create in their dialogue with one-another and where they fill the surface with content themselves (actively or passively) and thereby shape its functionality and meaning. Some of these systems will allow the functionality and content to drift over time and is flexible enough to allow for different norms, practices and behaviors to arise.

From a designer's perspective, one problem lies in how to strike a good balance between enabling the user to be an active co-constructor of system functionality where everything is kept completely open-ended versus making a too strong, interpretative design that does it all for the user thereby inhibiting their own creative use of the system.

Another problem lies in identifying which surfaces should be left open for the user. Not all functionality or content is accessible to and changeable by the users in the five systems presented above. It is, for example, not possible to add new recipe collections to Kalas, to change the circle of expressions in eMoto, or to change the mapping of sensors to the 'body'-shape in the Affective Diary. The decision about what to leave open for users to interpret, change, create and fill with their own content lies in the hands of the designer.

During the years, we have learnt some lessons on how to figure out which designs will have these qualities that we strive for.

\section{Natural but Designed}

While it may sound as if we are trying to build for some kind of 'naturalness', this is not necessarily our intention. Social communication and bodily experiences are shaped and re-shaped through experiences with one-another and with the world. Artifacts like the five systems above, will shape the communication, navigation, introspection or other activity that the application supports. An application is a designed artifact. It will enable certain activities and disable others. The communication with and through an application is mediated and people adapt to and learn how to deal with those possibilities and restrictions.

\section{Finding the Potentials for Familiar Open Surfaces}

In our experience, to find the applications and situations in which there is a potential for these kinds of design solutions to make sense - where a familiarity interpretation process can arise in and from the interaction - we need to look for the everyday experiences where the presence of others, their choices and their meaning-making processes are crucial to our own sense-making.

It can therefore be very important to study the everyday practices and everyday physical, bodily, encounters we have with the world [8, 12]. But another, sometimes equally fruitful path is to instead start from the design material: the technology available to us. The properties of the material itself raise a number of limiting conditions and possible openings. Only when experiencing the possibilities that this gives and how it feels when interacting with it, we can really see what makes sense. The problem is getting the technology into such a state that it can be experienced. Here we have been inspired by "Situated and Participative Enactment of Scenarios" by Iaccuci and colleagues [1920], that is, setting up situations with half-working systems that resemble the real situations in which they will be used.

Yet another guiding principle in our work has been to look critically examine existing design slogans. The work on social navigation and Kalas came from a critical study of 
navigation tools for large information spaces. At the time, most solutions referred to various forms of visualizations, maps in the interface, nice hierarchical organizations, and so on. In one of our studies we found huge differences in how effectively people could navigate those large spaces. Some took about 20 times longer to find their way than the most efficient users [6]. The solutions envisioned by most engineers and designers at the time, were typically relevant only to those who are already good at maps, thinking spatially, and organizing the world in structures. When we looked into how people actually find the information they need, it turned out to be a very social process - not at all as well-structured as we might think: hence the social navigation idea.

Another slogan we came across was the idea that network access of all kinds should always be seamlessly there. Users should not have to worry about it. But as it turns out, users do have to worry about it, partly because access in most networks is, and will be for a long time to come, unreliable and partly because of the heterogeneity of wireless network access technologies, such as WLAN, BlueTooth, GPRS, $3 \mathrm{G}$, WAP, or infrared connections just to mention a few. Yet another problem is the cost of different kinds of connections. Hence the idea of seamfulness and the attempt in MobiTip to make the underlying peer-to-peer BlueeToothenabled network at least somewhat understandable through the interface.

In both eMoto and Affective Diary we are questioning the prevailing affective computing endeavor setting out to identify, recognize, isolate and model human emotion processes. Our viewpoint is that emotions are embodied processes that we are deeply involved with and that cannot be separated from the context in which they are experienced (cf [21]). Instead, we are trying to make emotional communication, as in eMoto, open for users own expressivity and personality. The intention behind a sent eMoto can only be understood in the interpretation between the two communicating friends. The choice of gesture to express an emotion will vary with the user's own body language (even if our artifact only supports a small range of gestures).

In Affective Diary, the interpretation is more or less entirely open to users because of the simplistic mapping of sensors to the body shapes and colors. They read the representation almost like we read a horoscope. Through the combination of mobile and sensor materials, the diary is designed to invite reflection and to allow the user to piece together their own stories.

Both eMoto and Affective Diary are attempts from our end to involve users in an affective loop [30]. In an affective loop, we are designing for experiences where it is not possible to separate intellectual from sensual experiences; both are integrated in the application. In an affective loop, the user expresses her emotions through some physical medium, for example, through gestures or manipulations of an artifact or sensor-readings. The system (or another user through the system) then responds through generating affective expressions. This in turn affects the user making the user respond and step-by-step feel more and more involved with the system. But the main point is that the interpretation remains with the user.

\section{Opening Up for Appropriation and Creative Use}

In order for appropriation to happen, the activities of others have to be visible or accessible somehow and users need to have some power over how the system collects and displays their own activities. This never means that all the gory details of what is going on inside some application needs to be shown to the user. But the representation needs to be carefully chosen to make it somewhat transparent vis-à-vis its inner workings and its relationship to the physical and social surroundings [4, 17].

People will creatively and artfully making use of whatever material is around to express themselves to one-another. The Bluetooth-naming is there to make it possible to choose which device to connect to in order to create a communication link - it is not there to be used as "clothing" expressing the user's personality, and still, this is what happens in our example above.

There are of course problems with this perspective. Designers will always build their own intentions into the systems they produce. Users will sometimes (perhaps not as often as we would like to think) appropriate technology in ways that the designer had not anticipated. To deal with this we need to study the practice that arises around these designs and change the technology as we see how it is really used. It may be that we open certain "surfaces" to be read/written on (in the terminology of Suchman) while we should have been opening others.

\section{SUMMARY}

Our focus is on affective and social computing and our perspective is that of embodied interaction [8]. From studying social and affective communication practice as it unfolds between people in the world, we gain the basis for designing systems and artifacts that can serve as extensions of ourselves in interacting with others and ourselves. A specific focus lies in designing the systems in such a way that we leave some 'surfaces' open for users to fill with their own interpretation and practice. This does not mean that we design tools that are empty to start with and where the whole content is given by the user. Instead, we try to design ambiguous, abstract representation that open up for some kind of familiarity - in recognition of the representations from our daily social, emotional and bodily interactions with the world. But the applications we build will not make sense or have any meaning until users pick them and make them parts of their own practice, their own familiarity with their emotional, social, and bodily encounters with themselves and the world. 


\section{REFERENCES}

1. Asplund, J. (1987) Om hälsningsceremonier, mikromakt och asocial pratsamhet, Korpen, Göteborg: Graphic Systems.

2. Bjerknes, G. and Bratteteig, T. (1995) User Participation and Democracy: A Discussion of Scandinavian Research on System Development, Scandinavian Journal of Information Systems, 7(1):73-98.

3. Boehner, K., Chen, M., and Liu, Z. (2003) The Vibe Reflector: An Emergent Impression of Collective Experience. CHI 2003 Workshop on Providing Elegant Peripheral Awareness.

4. Brown, J. S. (1989). Toward a New Epistemology for Learning, In J. Frasson and J. Gauthiar (eds.), Intelligent Tutoring Systems in the Crossroads of Artificial Intelligence and Education, Norwood, NJ: Ablex Publishing.

5. Dahlbom, B. (2003). From Users to Consumers, In Scandinavian Journal of Information Systems, vol 15.

6. Dahlbäck, N., Höök, K. and Sjölinder, M. (1996). Spatial Cognition in the Mind and in the World: The case of hypermedia navigation, The Eighteenth Annual Meeting of the Cognitive Science Society, UC, San Diego.

7. Damasio, A. R. (1994) Descartes' error: emotion, reason, and the human brain, GP Putnam, New York.

8. Dourish, P. (2001). Where the Action Is: The Foundations of Embodied Interaction. MIT Press.

9. Espinoza, F., Persson, P., Sandin, A., Nyström, H., Cacciatore. E. \& Bylund, M., (2001). GeoNotes: Social and Navigational Aspects of Location-Based Information Systems, In Ubicomp 2001: Ubiquitous Computing, International Conference Berlin: Springer, pp. 2-17.

10. Fagerberg, P., Espinoza, F., Persson, P. (2003).What is a place? Allowing users to name and define places. Ext. Abstracts CHI 2003, ACM Press, pp. 828-829.

11.Fagerberg, P., Ståhl, A., and Höök, K. (2003) Designing gestures for affective input: an analysis of shape, effort and valence, In Proceedings of MUM 2003, ACM Press.

12. Fällman, D. 2003. In romance with the materials of mobile interaction. Unpublished Doctoral Thesis, Department of Informatics, Umeå University, Umeå, Sweden.

13. Friedman, B. (2004). Value Sensitive Design. In Encyclopedia of human-computer interaction. (pp. 769-774). Great Barrington, MA: Berkshire Publishing Group.

14. Gaver, W.W. (2002). Designing for Homo Ludens. I3 Magazine No. 12, June 2002.

15. Gaver, W., Beaver. J. and Benford, S. (2003). Ambiguity as a resource for design, Proc. of the Conf on Human factors in computing systems, ACM Press.

16. Harrison, S., and Dourish, P. (1996). Re-place-ing space: The roles of space and place in collaborative systems. Proceedings of CSCW'96, 67-76. ACM Press.
17.Höök, K. (1996), A Glass Box Approach to Adaptive Hypermedia, Unpublished Doctoral Thesis, Dept. of Computer and Systems Sciences, Stockholm University.

18. Höök, K. (2000) Steps to take before IUIs become real, Journal of Interacting with Computers, vol. 12, no. 4, pp. 409-426.

19. Iacucci, G. and Kuutti, K. (2002) Everyday life as a stage in creating and performing scenarios for wireless devices. Personal and Ubiquitous Computing Journal, vol. 6, pp. 299-306.

20. Iacucci, G., Kuutti, K. and Ranta, M. (2000) On the move with a magic thing: role playing in concept design of mobile services and devices, In Proceedings of the conference on Designing interactive systems, pp. 193 202, ACM Press.

21. Katz, J. (1999) How Emotions Work, Chicago, IL: University of Chicago Press.

22.Lindström, M., Ståhl, A., Höök, K., Sundström, P., Laaksolahti, J., Combetto, M., Taylor, A., and Bresin, R. (2006). Affective Diary - Designing for Bodily Expressiveness and Self-Reflection, In Proc. of CHI 2006, Work in Progress paper, ACM. (Extended abstract)

23. McCarthy, J. and Wright, P. (2004). Technology as Experience. MIT Press.

24.Picard, R. W. (1997). Affective Computing, MIT Press, Cambridge, MA, USA.

25. Rudström, Å. (2005). Co-Construction of Hybrid Spaces. Unpublished Doctoral thesis, Department of Computer and Systems Science, Stockholm University.

26. Rudström, Å., Höök, K. and Svensson, M. (2005). Social positioning: Designing the Seams between Social, Physical and Digital Space. In 1st International Conference on Online Communities and Social Computing, HCII 2005, Lawrence Erlbaum.

27.Sengers, P., Boehner, K., David, S., Kaye, J. (2005). Reflective Design. Proceedings of the $4^{\text {th }}$ Decennial Aarhus Conference on Critical Computing. Aarhus, Denmark. ACM Press.

28. Schuler, D. and Namioka, A. (Eds.), 1993. Participatory Design: principles and practices. Hillsdale, NJ: Lawrence Erlbaum Associates.

29. Suchman, L. (1987). Plans and Situated Actions. The Problem of Human Machine Communication. Cambridge University Press.

30. Sundström, P, Ståhl, A. and Höök, K. (forthcoming) In Situ Informants Exploring an Emotional Mobile Messaging System in Their Everyday Practice, submitted.

31.Svensson, M., Höök, K. and Cöster R. (2005). Designing and Evaluating Kalas: a Social Navigation System for Food Recipes, In ACM Transactions on ComputerHuman Interaction, ACM Press, Sept. Issue. 
The columns on the last page should be of approximately equal length. 